\title{
COVID Eyes: REM in COVID-19 Survivors
}

\author{
Abhishek Goyal ${ }^{1} \cdot$ Avishek Kar $^{1} \cdot$ Khushboo Saxena $^{1}$ \\ Received: 29 November 2020 / Accepted: 16 December 2020 / Published online: 11 January 2021 \\ (c) The Author(s), under exclusive licence to Springer Nature Singapore Pte Ltd. part of Springer Nature 2021
}

\begin{abstract}
Increased REM density and alpha intrusion are routinely seen in COVID-19 patient. These findings may correlate with unstable sleep pattern in COVID-19 survivors and therefore, sleep hygiene and proper counselling should be emphasized upon. Clinicians and technicians should be aware of these EEG changes with reference to COVID-19 survivors in interpreting polysomnography.
\end{abstract}

Keywords COVID-19 $\cdot$ Sleep $\cdot$ REM density $\cdot$ Alpha intrusion

A 58-year-old male, known case of hypertension, diabetes mellitus was admitted with COVID-19 ARDS in ICU. Patient denied any history of depression or insomnia before contracting COVID-19 infection. After one month of discharge from ward, he underwent level I polysomnography (Alice 6, Philips, USA) as part of research study with all necessary precautions and permissions. His BMI was $24.4 \mathrm{~kg} / \mathrm{m}^{2}$.

ON polysomnography, sleep efficiency was $72.8 \%$. N1, N2, N3 and REM constituted 9.1, 68.1, 2.1 and 20.6\% of total sleep time, respectively. Patient had moderate obstructive sleep apnoea and his AHI was 19.3/h. Patient was advised to use automatic continuous positive airway pressure.

Images during rapid eye movement (REM) sleep are shown (Figs. 1, 2). Average number of REM movements per minute was 14.48 per minute. REM density was 12.6 , $10,13.6$ and 30.4 per minute in consecutive sleep cycles. Excessive REM density (characterised by increased REM movements) and increased REM amplitude (up to $300 \mu \mathrm{V}$ ) were seen (Fig. 1).

REM density is usually defined by number of rapid eye movements per epoch of REM sleep. Average REM density seen in normal healthy subjects was $2.9-8.86$ per minute in our lab (unpublished data). Increased REM density has been reported in patients with depression. Increased REM density

Abhishek Goyal

abhishek.pulmed@aiimsbhopal.edu.in

1 Department of Pulmonary Medicine, All India Institute of Medical Sciences, Bhopal, India has also been associated with poor prognosis in various psychiatric disorders like suicidality in schizophrenia, relapse in recovering alcoholics, and poor response to antidepressant in depression [1]. In this case, patient screened negative for insomnia (Insomnia Severity Index Score-6/28) and depression (Patient Health Questionnaire-4 for Anxiety and Depression score of 0/12) on the day of sleep study.

Alpha intrusion was seen in non-rapid eye movement (NREM) as well as REM stages in this patient. Alpha intrusion has been reported in psychiatric disorders like fibromyalgia, depression, chronic fatigue syndrome, anxiety disorder, and primary sleep disorders like psychophysiological insomnia, obstructive sleep apnea, circadian disorders and narcolepsy. REM alpha bursts (alpha activity lasting at least $3 \mathrm{~s}$ without an increase in EMG amplitude) may represent microarousals (Fig. 2) [2, 3].

It would be too early to conclude that these changes are primarily due to viral infection. Effect of viral infection on human sleep has not been widely studied. However, few studies have noted that effect of viruses on REM stage is variable. Intranasal inoculation with influenza virus in mice has been shown to enhance NREM and decrease REM [4]. Sleep study in patients with HIV virus has shown normal REM density and reduced REM time [5, 6]. Patients of poliovirus develop obstructive sleep apnoea later in their lives due to involvement of upper airway muscles.

We are currently doing polysomnography in COVID-19 survivors (after 4 weeks of discharge) who were admitted in our hospital as part of research study. In our experience, increased REM density and REM alpha intrusion are routinely seen in COVID-19 patients. Whether these changes 


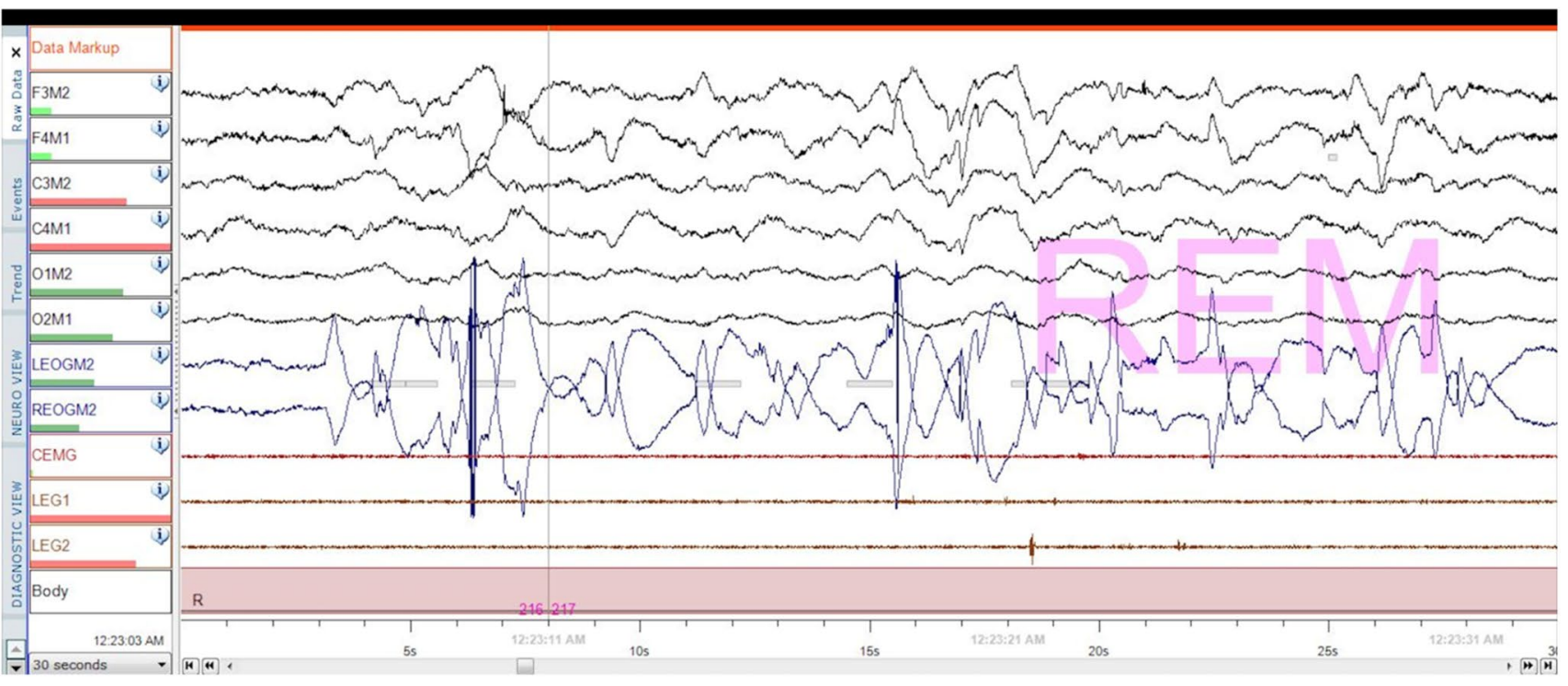

Fig. 1 Rapid eye movements showing increased REM density

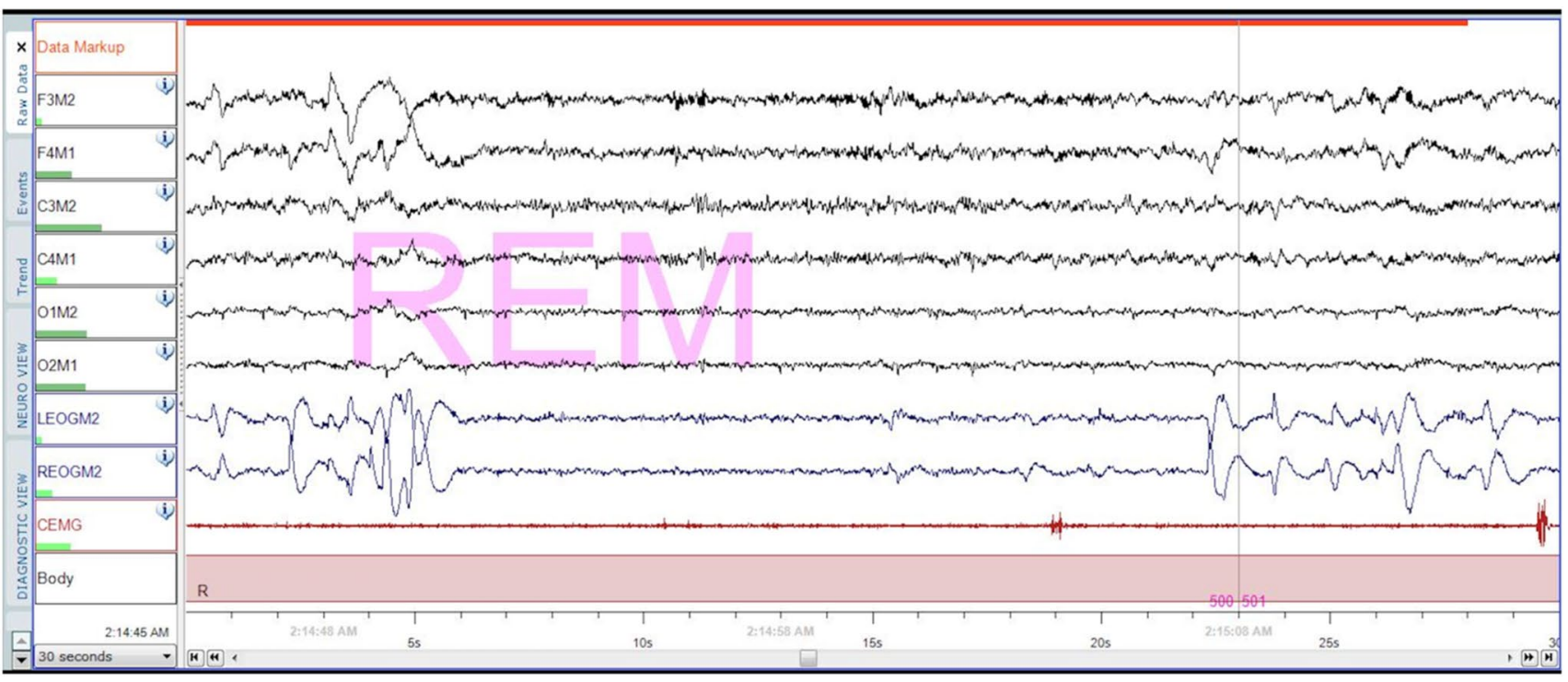

Fig. 2 REM periods interspersed with alpha intrusion (REM alpha bursts)

are transient or persist after few months needs further evaluation.
Author Contributions All authors have seen and approved the manuscript.

\section{Compliance with Ethical Standards}

Conflict of interest no conflict of interest. 


\section{References}

1. Clark C, Dupont R, Golshan S, Gillin JC, Rapaport MH, Kelsoe JR. Preliminary evidence of an association between increased REM density and poor antidepressant response to partial sleep deprivation. J Affect Disord. 2000;59:77-83.

2. Shetty S, Le T. Medical image of the week: alpha intrusion into REM sleep. Southwest J Pulm Crit Care. 2015;11:273-4.

3. Cantero JL, Atienza M. Alpha burst activity during human REM sleep: descriptive study and functional hypotheses. ClinNeurophysiol. 2000;111:909-15.

4. Ibarra-Coronado EG, Pantaleón-Martínez AM, Velazquéz-Moctezuma J, et al. The bidirectional relationship between sleep and immunity against infections. J Immunol Res. 2015;2015:1-14.
5. Wiegand M, Möller AA, Schreiber W, et al. Nocturnal sleep EEG in patients with HIV infection. Eur Arch Psychiatry ClinNeurosci. 1991;240:153-8.

6. Fang J, Tooley D, Gatewood C, Renegar KB, Majde JA, Krueger JM. Differential effects of total and upper airway influenza viral infection on sleep in mice. Sleep. 1996;19:337-42.

Publisher's Note Springer Nature remains neutral with regard to jurisdictional claims in published maps and institutional affiliations. 